\title{
Significance of bacteria in oviposition and larval development of the sand fly Lutzomyia longipalpis
}

\author{
Kamila Peterkova-Koci', Maricela Robles-Murguia', Marcelo Ramalho-Ortigao ${ }^{1}$ and Ludek Zurek ${ }^{1,2^{*}}$
}

\begin{abstract}
Background: Microbial ecology of phlebotomine sand flies is not well understood although bacteria likely play an important role in the sand fly biology and vector capacity for Leishmania parasites. In this study, we assessed the significance of the microbial community of rabbit feces in oviposition and larval development of Lutzomyia longipalpis as well as bacterial colonization of the gut of freshly emerged flies.

Methods: Sterile (by autoclaving) and non-sterile (control) rabbit feces were used in the two-choice assay to determine their oviposition attractiveness to sand fly females. Bacteria were identified by amplification and sequencing of the 165 rRNA gene with universal eubacterial primers. Sterile, control (non-sterile), and sterilized and inoculated rabbit feces were used to assess the significance of bacteria in L. longipalpis development. Newly emerged adult flies were surface-sterilized and screened for the bacterial population size and diversity by the culturing approach. The digestive tract of $L 4$ sterile and control larvae was incubated with Phalloidin to visualize muscle tissues and DAPI to visualize nuclei.
\end{abstract}

Results: Two-choice behavioural assays revealed a great preference of $L$. longipalpis to lay eggs on rabbit feces with an active complex bacterial community (control) (85.8\% of eggs) in comparison to that of sterile (autoclaved) rabbit feces (14.2\%). Bioassays demonstrated that L. longipalpis larvae can develop in sterile rabbit feces although development time to adult stage was greatly extended (47 days) and survival of larvae was significantly lower (77.8\%) compared to that of larvae developing in the control rabbit feces (32 days and $91.7 \%$ ). Larval survival on sterilized rabbit feces inoculated with the individual bacterial isolates originating from this substrate varied greatly depending on a bacterial strain. Rhizobium radiobacter supported larval development to adult stage into the greatest extent (39 days, $88.0 \%$ ) in contrast to that of Bacillus spp. (76 days, $36.0 \%$ ). From the complex natural bacterial community of rabbit feces, $R$. radiobacter survived pupation and colonized the newly emerged females most successfully ( $82.6 \%$ of all bacteria cultured); however, only $25 \%$ of females were positive for bacteria in the digestive tract upon emergence. Immunohistochemistry did not reveal any obvious differences in anatomy of the digestive tract between control and axenic larvae.

Conclusions: The bacterial community in the sand fly larval habitat affects oviposition and larval development although bacteria are not essential for successful development of L. longipalpis. Different bacteria contribute to larval development to various degrees and some, e.g. Rhizobium radiobacter, survive pupation and colonize the digestive tract of newly emerged females. With the establishment of the axenic rearing system, this study opens new venues to study the effect of bacteria on the gut epithelial immunity and vector competence of sand flies for Leishmania parasites with a goal to develop paratransgenic approaches for Leishmania control.

Keywords: Sand flies, Lutzomyia longipalpis, Bacteria, Oviposition, Larval development, Rabbit feces

\footnotetext{
* Correspondence: Izurek@ksu.edu

'Department of Entomology, Kansas State University, 123 Waters Hall,

Manhattan, KS, USA

${ }^{2}$ Department of Diagnostic Medicine and Pathobiology, Kansas State

University, 123 Waters Hall, Manhattan, KS, USA
}

\section{Biomed Central}

(c) 2012 Peterkova-Koci et al.; licensee BioMed Central Ltd. This is an Open Access article distributed under the terms of the Creative Commons Attribution License (http://creativecommons.org/licenses/by/2.0), which permits unrestricted use, distribution, and reproduction in any medium, provided the original work is properly cited. 


\section{Background}

The phlebotomine sand fly Lutzomyia longipalpis (Diptera: Psychodidae) is an important biological vector of Leishmania infantum (syn. Leishmania chagasi) in Central and South America. Although very little is known about the larval habitat of sand flies, it is generally agreed that organic material is the main food source for larvae [1]. The larval habitat likely includes feces of rabbits and rodents in underground burrows where the proper temperature and humidity are maintained [2]. Rabbit feces contain a large and diverse microbial community $[3,4]$ that potentially plays an important role in: a) sand fly oviposition behavior as bacterial volatile compounds may be used as semiochemical cues for females to locate the suitable habitat for their offspring; b) sand fly larval development since bacteria may provide essential or additional nutrients; and c) vector competence of sand flies for Leishmania parasites as bacteria surviving pupation and colonizing the gut of newly emerged females may influence development and transmission of the parasites.

It has been demonstrated that animal feces, including that of rabbits, play a role in L. longipalpis oviposition behavior and the active chemicals for the attraction are hexanal and 2-methyl-2-butanol [5,6]. Additional oviposition attractant and/or stimulant for L. longipalpis includes dodecanoic acid deposited on eggs from the female accessory glands [7-9]. Furthermore, frass of the larvae also positively affected L. longipalpis oviposition [10]. While the bacterial community in animal feces is likely a major player influencing sand fly oviposition behavior, only one study addressed this topic and showed that bacterial isolates from the soil in the natural breeding habitat of Phlebotomus papatasi attracted gravid females [11].

Virtually nothing is known about the significance of bacteria in the larval development of sand flies. It has been shown for several other Diptera including stable flies [12], house flies [13], horn flies [14], and face flies [15] that live bacteria are essential for successful larval development although the basis of this dependence on microbes remains unknown.

While bacteria in the lumen of the digestive tract do not typically survive insect pupation, it has been reported that freshly emerged female mosquitoes Anopheles gambiae and A. stephensi [16] and sand flies $P$. duboscqi [17] and $P$. argentipes [18] had live bacteria in the digestive tract.

This study was designed to determine the significance of bacteria in rabbit feces in oviposition and larval development of L. longipalpis as well as to assess the extent of bacterial survival during sand fly pupation.

\section{Methods}

\section{Sand flies and rabbit feces}

A laboratory colony of Lutzomyia longipalpis from Jacobina, Brazil was used in this study. Flies were maintained at $27 \pm 1{ }^{\circ} \mathrm{C}$ and $75 \pm 5 \%$ humidity. Adults were given a $20 \%$ sucrose solution ad libitum and females were blood-fed twice a week on anesthetized mouse to produce eggs. For all experiments, fresh $(<24 \mathrm{hrs})$ rabbit feces from domestic rabbits kept in outdoor pens and fed alfalfa/corn rabbit pellets and grass garden clippings or bromegrass hay, were used for the assays.

\section{Oviposition assay}

In two-choice assays, sterile (by autoclaving) and nonsterile (control) rabbit feces were used to determine their oviposition attractiveness to sand fly females. Individual blood-fed females were placed in the plastic ovipots $(\varnothing=10 \mathrm{~cm}$, height $=7 \mathrm{~cm})$ with plaster on the bottom and $1.0 \mathrm{~g}$ of each, sterile and control rabbit feces on opposite sides of the ovipot. Before each assay, humidity of rabbit feces was measured and adjusted to be the same (65-70 \%) for both substrates using sterile tap water. Number of eggs on each substrate was recorded after $24 \mathrm{hrs}$. Nine individual females were used in each bioassay and each assay was replicated five times. At the end of each assay, rabbit feces of each type (control and sterilized) from two ovipots were sampled, diluted in phosphate-buffered saline (PBS) (pH 7.2; MP Biomedicals), and plated on broad spectrum medium, trypticase soy broth agar (TSBA) (BBL, Sparks) to assess the extent of contamination of sterilized feces by the flies during the assay.

\section{Isolation and identification of bacteria}

Fresh ( $<24$ hrs) rabbit feces were brought to the laboratory in a sterile plastic bag and processed immediately. For the isolation of bacteria, $10 \mathrm{~g}$ of feces was suspended in $40 \mathrm{ml}$ of PBS, serially diluted in PBS, and dilutions were plated onto TSBA, and two selective and differentiating media, MacConkey agar (MAC) and modified Enterococcus agar (mENT) (BBL, Sparks). Plates were then incubated aerobically at $26{ }^{\circ} \mathrm{C}$ (TSBA), $37{ }^{\circ} \mathrm{C}$ (MAC) and $42{ }^{\circ} \mathrm{C}$ (mENT) for 48-72 h. Morphologically different single colonies were isolated on TSBA and stored at $4{ }^{\circ} \mathrm{C}$ until further analysis. Bacteria were identified by amplification and sequencing of the 16S rRNA gene with universal eubacterial primers: 8F (5'-AGAGTTTGATCC TGGCT CAG-3') and 806R (5'- CTACCAGGGTATCTAAT-3') [19] following the standard protocols. Isolates from mENT (enterococci) were identified by amplification and sequencing of the manganese-dependent superoxide dismutase gene $(\operatorname{sod} A)[20]$. Sequences were manually edited in CodonCode Aligner (version 1.3.4) (CodonCode Corporation) and identified by BLAST (Basic Local Alignment Search Tool) [21] search of the GenBank database. 


\section{Larval development assay}

Four day old sand fly eggs were surface-sterilized with $0.05 \%$ sodium hypochlorite and $70 \%$ ethanol [13] and placed on TSBA plate until hatching to confirm the surface sterility. Newly hatched larvae (five per plate) were transferred by sterile brush in Petri plates with sterile water agar base. Water agar (1.4\%) was used to maintain appropriate moisture in the plates. For the control group, fresh rabbit feces grounded with mortar and pestle were provided ad libitum. For the axenic group, grounded fresh rabbit feces were sterilized by autoclaving and offered ad libitum. To assess the contribution of bacteria to larval development, sterile feces were inoculated with different bacterial isolates suspended in PBS ( $10^{6} \mathrm{CFU}$ per ml). Humidity of each substrate was measured before assays and adjusted by sterile PBS. Plates were kept at $26{ }^{\circ} \mathrm{C}$ and $40 \pm 5 \%$ humidity until adult emergence. Mortality and development time to pupation and adult emergence were monitored on a daily basis. Each assay was conducted in 5 replicates (inoculated rabbit feces) or in 12 replicates (sterile and control feces). Three plates with sterile feces were discarded due to microbial contamination. Sterility of the substrate in the axenic system was confirmed by plating $(100 \mu \mathrm{l})$ of the rabbit feces ( $1 \mathrm{~g}$ suspended in $10 \mathrm{ml}$ PBS) on TSBA at the end of the assay. To assess the fitness of adult flies from the axenic group, they were fed sterile $20 \%$ sucrose solution offered on sterilized filter papers for 3 days.

\section{Survival of bacteria during sand fly pupation}

Newly emerged flies were surface-sterilized (as described above), homogenized by hand using pestles in $100 \mu \mathrm{l}$ PBS and plated on TSBA maintained at $26{ }^{\circ} \mathrm{C}$ under aerobic conditions. Bacterial counts (CFU per fly) were determined and bacterial colonies with distinct morphologies were sub-cultured and identified by amplification and sequencing of the $16 \mathrm{~S}$ rRNA gene as described above. Sterility of axenic females was confirmed by plating the fly homogenate on TSBA and by DNA extraction and amplification of $16 \mathrm{~S}$ rDNA with universal primers as described above.

\section{Gut immunohistochemistry}

The digestive tract of L4 larvae was dissected in PBS and incubated for $10 \mathrm{~min}$ in dark with Alexa Fluor 546 Phalloidin (Molecular Probes) to visualize muscle tissues (Actin) and DAPI (4', 6-diamidino-2-phenylindole) (Sigma) to visualize nuclei. Samples were observed under the compound microscope (Nikon Eclipse E800) with epifluorescent UV light and appropriate filters. Four

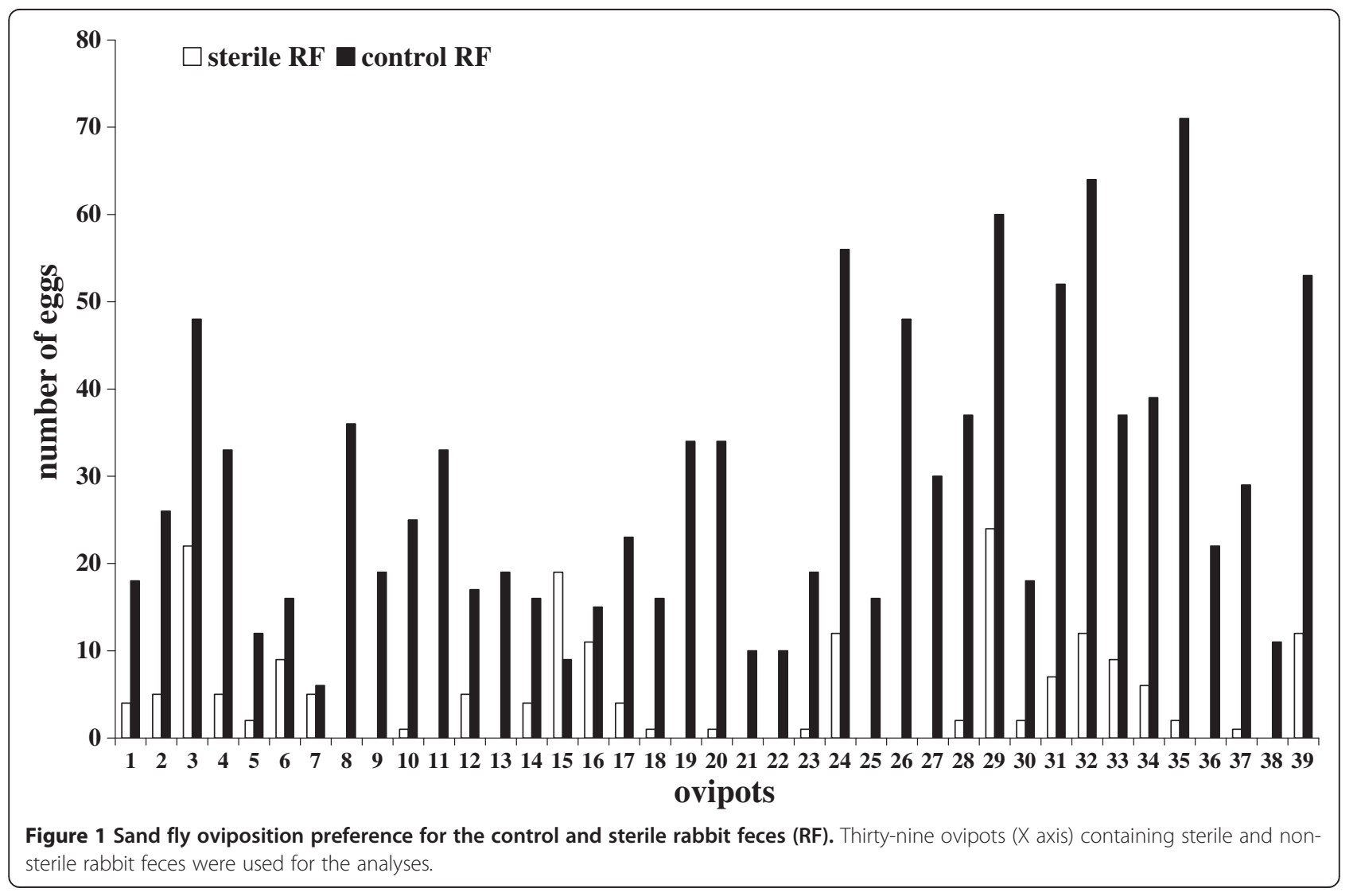


individual digestive tracts from each group (control and axenic) were analyzed.

\section{Statistical analysis}

One-way ANOVA test was used to assess significance of differences in mortality and development time among flies in different treatments using Origin 7 (OriginLab Corp.). If ANOVA revealed significant differences $(P \leq 0.05)$ among treatments, pairwise comparisons were conducted using Tukey test in Origin 7 to assign groupings.

\section{Results and Discussion}

Analysis of oviposition response of sand fly females to sterile and control rabbit feces showed a clear preference to feces with a live and complex microbial community (Figure 1$)$. The majority of eggs $(85.8 \%)$ were laid on or very near control rabbit feces $(29.2 \pm 16.9$ eggs per female) in comparison to sterile feces where only $14.2 \%$ of eggs were oviposited (4.8 \pm 6.2 eggs per female). Although the sterilized feces did not remain sterile at the end of the assay (after 24 hrs) due to contamination by the sand flies, the difference in concentration was obvious $\left(\sim 10^{6} \mathrm{CFU}\right.$ per gram [control] versus $\sim 10^{2} \mathrm{CFU}$ per gram [sterilized]). These data clearly show that the live bacterial community in rabbit feces produces chemical cues that serve as attractant and/or stimulant for oviposition of L. longipalpis. Whether these cues are volatile or serve as contact semiochemicals needs to be assessed in future studies. Previously, two compounds originating from rabbit feces reported as oviposition attractants were hexanal and 2-methyl-2-butanol [22]. Hexanal is a bi-product of lipid oxidation and not likely of the microbial origin. On the other hand, 2-methyl-2-butanol, is generated by microbial fermentation supporting the notion that the microbial community generates oviposition attractants or stimulants. Nevertheless, the key bacterial taxa and their metabolic products affecting sand fly oviposition behavior remain to be determined. Autoclaving not only sterilized the substrate and killed the microbes but likely affected biological and chemical properties of the rabbit feces and consequently volatile compounds. However, the sterilized feces were not used for oviposition assays for $24 \mathrm{hrs}$ after autoclaving in order to cool down and allow for exchange of the headspace air. Our previous study [12] using the same approach to assess the significance of bacteria in horse feces in oviposition of stable flies, demonstrated that inoculation of autoclaved feces with bacterial isolates restored the oviposition attractiveness of this substrate. While this remains to be shown for sand flies, it supports the notion that it is bacterial volatiles that are used as cues for insect oviposition.

The following seventeen bacterial isolates from fresh rabbit feces with different colony morphology were identified to the species or genus level by sequencing of the 16S rRNA gene (655-698 bp) or the sodA gene (438 bp): Bacillus firmus (98 \% identity), Bacillus sp. KK-1 (99 \%); Enterococcus avium (99\%); Enterococcus gallinarum (99\%); Curtobacteriun flaccumfaciens (99\%); Microbacterium foliorum (98 \%), Arthrobacter bergeri (99 \%), Arthrobacter sp. (99\%), Acinetobacter sp. (99 \%); Citrobacter freundii (99\%), Morganella morganii (99 \%), Escherichia coli (99\%), Klebsiella sp. (99\%), Enterobacter sp. (97 \%), Pseudomonas sp. KK-1 (99 \%), Pseudomonas sp. KK-2 (99\%), and Rhizobium radiobacter (100\%). Analysis of the isolates from the digestive tract of freshly emerged sand fly females that developed as larvae in control rabbit feces led to identification of two additional bacterial taxa, Mycobacterium phocaicum

Table 1 Development of $L$. longipalpis in rabbit feces (RF) with different treatments and prevalence and concentration of bacteria in the gut of newly emerged females

\begin{tabular}{lcccc}
\hline Substrate & $\begin{array}{l}\mathbf{1}^{\text {st }} \\
\text { instar } \\
\text { larvae } \\
\text { (n) }\end{array}$ & $\begin{array}{l}\text { \% survival to } \\
\text { adult stage } \\
\text { (\% females) }\end{array}$ & $\begin{array}{l}\text { \% newly emerged } \\
\text { females with } \\
\text { bacteria in the gut }\end{array}$ & $\begin{array}{l}\text { Mean } \\
\text { concentration } \\
\text { of bacteria } \\
\text { (CFU } \pm \text { SEM) } \\
\text { per female }\end{array}$ \\
\hline Control RF & 60 & $91.7(50.9)^{\mathrm{a}}$ & $1.4 \pm 0.9 \times 10^{1}$ \\
Sterile RF & 45 & $77.8(48.6)^{\mathrm{b}}$ & 25.0 & 0 \\
Morganella morgani & 25 & $76.0(52.6)^{\mathrm{b}}$ & 4 & $1.6 \pm 1.5 \times 10^{3}$ \\
Pseudomonas sp. KK-2 & 25 & $72.0(55.6)^{\mathrm{b}}$ & 40.0 & $3.2 \pm 2.6 \times 10^{2}$ \\
Pseudomonas sp. KK-1 & 25 & $84.0(38.1)^{\mathrm{a}}$ & 25.0 & $2.0 \pm 1.2 \times 10^{3}$ \\
Rhizobacterium radiobacter & 25 & $88.0(40.9)^{\mathrm{a}}$ & 33.3 & $1.8 \pm 1.3 \times 10^{3}$ \\
Enterococcus gallinarum & 25 & $84.0(76.2)^{\mathrm{a}}$ & 6.3 & $8.3 \times 10^{1}$ \\
Bacillus sp. KK-1 & 25 & $36.0(22.2)^{\mathrm{c}}$ & 0 & 0 \\
six bacterial isolates together & 25 & $84.0(42.9)^{\mathrm{a}}$ & 44.4 & $2.8 \pm 2.3 \times 10^{2^{*}}$ \\
\hline
\end{tabular}

CFU = colony forming units; different letters in superscript indicate significant difference among treatments.

\# only females positive for bacteria are included, SEM = standard error of mean, *bacterial diversity shown in Figure 3. 
(99 \%) and Acidovorax sp. (99 \%). Most of these bacteria are common members of the mammalian gastrointestinal tract and some likely originate from the rabbit environment (soil) and feed (grass clippings and hay). Several bacterial species reported in our study including Pseudomonas, Citrobacter, Enterobacter, Escherichia, Klebsiella, and Morganella sp. were detected previously by culturing approach in the midgut of wild L. longipalpis collected from three sites in Brazil [23]. A similar bacterial community was also found by culturing of the gut bacteria from $P$. argentipes in India [24] although in this study, higher prevalence of Gram-positive taxa ( $\mathrm{Ba}$ cillus, Staphylococcus, Micrococcus sp.) was found compared to that of Gouveia et al. [23].

Mortality (22.2\%) was significantly higher and development time to adult stage $(47.4 \pm 9.1$ days $)$ was significantly longer in larvae maintained in axenic (sterile) rabbit feces compared to that of larvae in control rabbit feces with a live and complex microbial community (8.3\% mortality, $31.8 \pm 4.8$ days development time) (Table 1, Figure 2). Six bacterial isolates identified from fresh rabbit feces were selected for larval developmental assay to evaluate their significance in L. longipalpis development individually and in combination. Several individual bacterial isolates including Pseudomonas sp. KK-1 , Rhizobium radiobacter, Enterococcus gallinarum, and all six isolates together supported development of $L$. longipalpis larvae to adult stage into the similar extent (mortality not significantly different) as the entire microbial community (control rabbit feces) (Table 1). Mortality of larvae grown on rabbit feces with Morganella morganii and Pseudomonas sp. KK-2 was significantly higher than that on control rabbit feces (Table 1). From the development time perspective $\left(1^{\text {st }}\right.$ instar to adult stage), among all individual isolates, feces with $M$. morganii led to the shortest development time $(33.9 \pm 2.8$ days $)$ not significantly different from that of control rabbit feces. In contrast, development with $E$. gallinarum was long and not significantly different from that of sterile feces (Figure 2). Bacillus sp. KK-1 supported the development of sand fly larvae the least, resulting in very high mortality (64\%) and significantly longer development time (75.6 \pm 7.2 days) compared to that of all other treatments (Table 1, Figure 2).

The basis of bacterial contribution to sand fly larval development is unknown; it may include breakdown of the components of rabbit feces to more digestible and absorbable nutrients and/or production of additional nutrients such as vitamins and amino acids. Although bacterial cells may be digestible in the gut of sand fly larvae and may serve as a source of nutrients, the bacterial cells mass alone (no additional food sources) does not support larval development (data not shown). It is important to emphasize that this study focused on the bacterial community only and other microorganisms including fungi and protozoa may also play a role in sand fly oviposition and larval development.

To our knowledge, the organization of the internal organs of sand fly larvae has not been reported with the exception of the study by Fazio do Vale et al. [25], showing anatomy of the gut of L. longipalpis and where $\mathrm{pH}$ gradient and several proteinases in the midgut were measured. Here we show the L4 digestive tract, salivary glands, fat body (one side only), and Malpighian tubules (one side only) in the drawing based on our microscopy (Figure 3). We did not observe any obvious differences in the gut size between axenic and control larvae. In addition, our preliminary observation of the gut

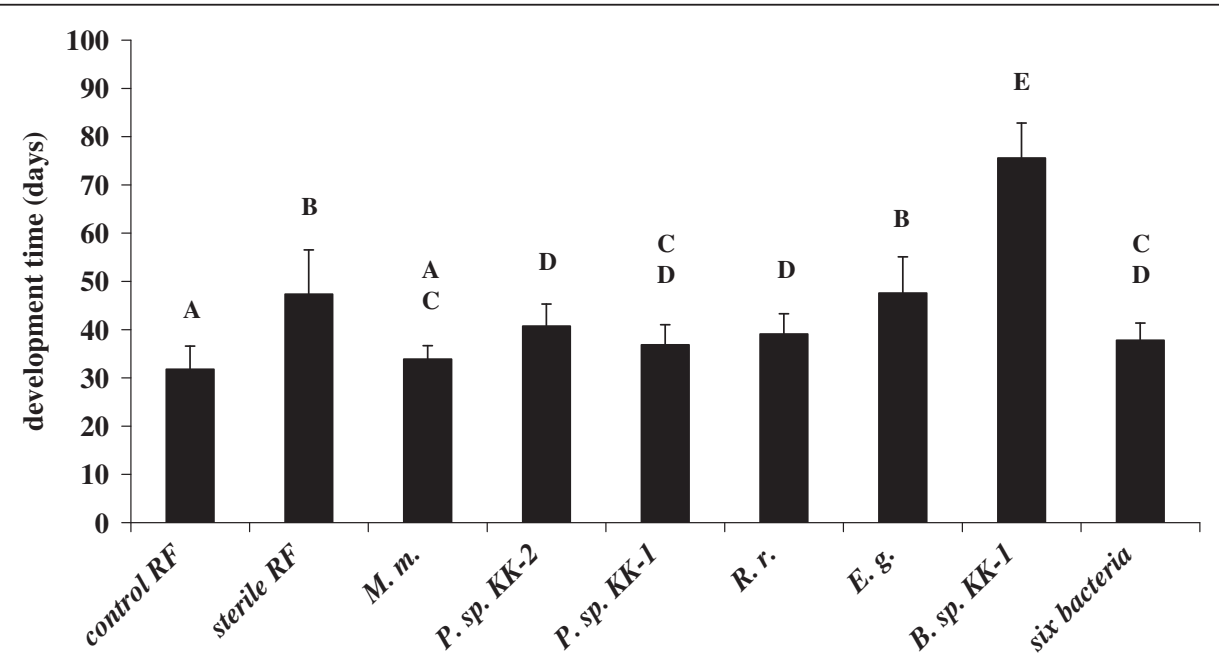

Figure 2 Development time (mean + SEM) of sand flies reared on sterile rabbit feces inoculated with various bacterial isolates. RF rabbit feces; M. m. - Morganella morganii; P. sp. KK-2 - Pseudomonas sp. KK-2; P. sp. KK-1 - Pseudomonas sp. KK-1; R .r. - Rhizobium radiobacter; E. g. Enterococcus gallinarum; $B$. sp. KK-1 - Bacillus sp. KK-1. Different letters above error bars indicate significant differences $(P \leq 0.05)$. 


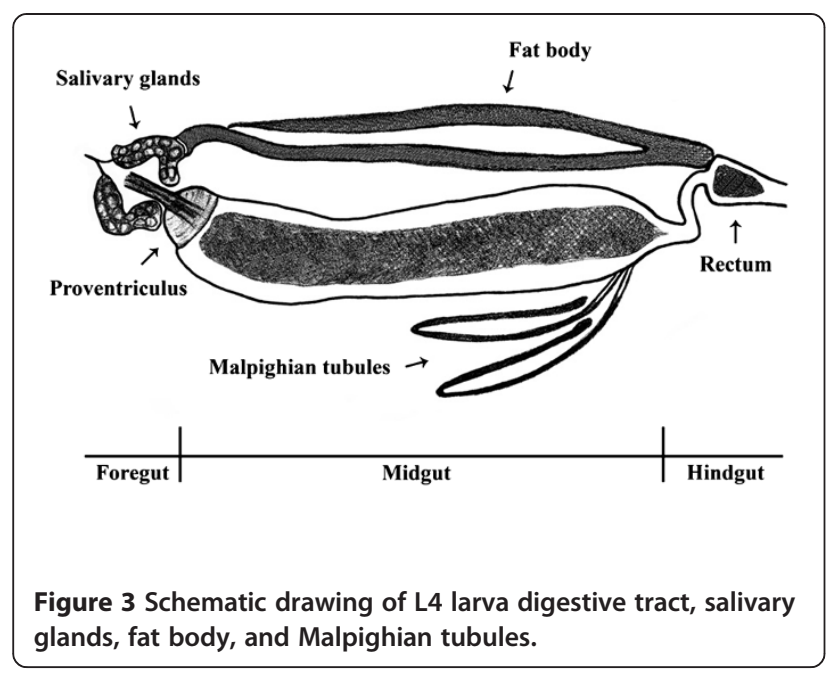

Figure 3 Schematic drawing of L4 larva digestive tract, salivary
glands, fat body, and Malpighian tubules. structure including muscle tissue (actin staining with phalloidin) and epithelium (nuclei staining with DAPI) (Figure 4) did not indicate any obvious differences between axenic and control larvae. However, this remains to be examined in more details. We also did not detect any noticeable differences between axenic and control adult sand flies in regards to body size, sugar feeding, and mortality. Since we dissected axenic adult flies either immediately after emergence or after 3 days of sucrose feeding to confirm sterility of the digestive tract, overall adult life span, blood feeding, and fecundity of axenic females are unknown and will be addressed in our future studies.

Newly emerged females that developed as larvae in control rabbit feces with an active and complex bacterial community had live bacteria in the digestive tract although the prevalence was low ( $25 \%$ of flies) and the bacterial community size $\left(8.3 \times 10^{1}\right.$ to $2.0 \times 10^{3}$ CFU per gut) and diversity were also low (Table 1, Figure 5A).
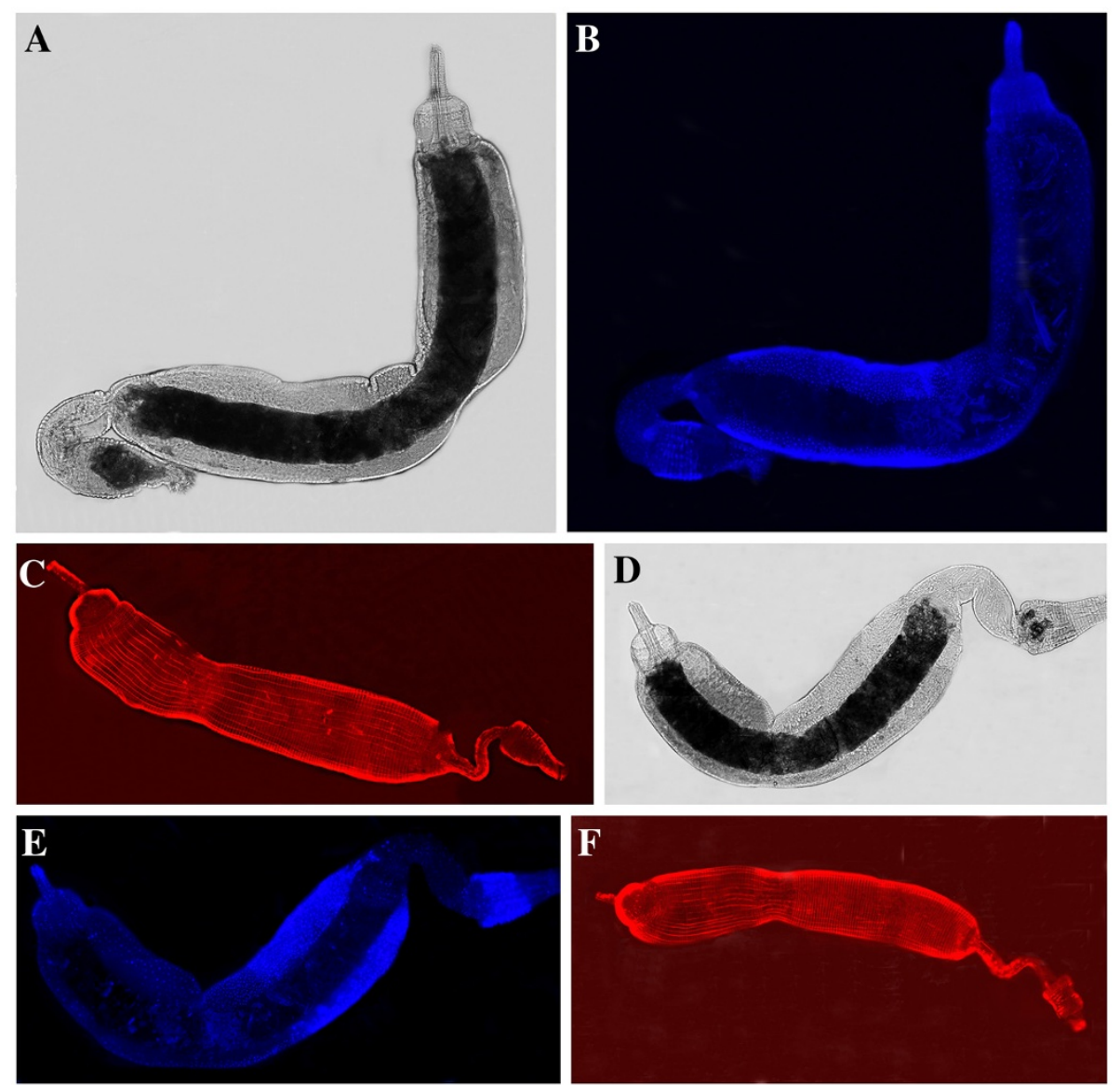

Figure 4 Immunohistochemistry of the larval (L4) digestive tract: Control larva: (A1) regular light, (A2) DAPI staining, (A3) phalloidin staining; Axenic larva: (B1) regular light, (B2) DAPI staining, (B3) phalloidin staining. 

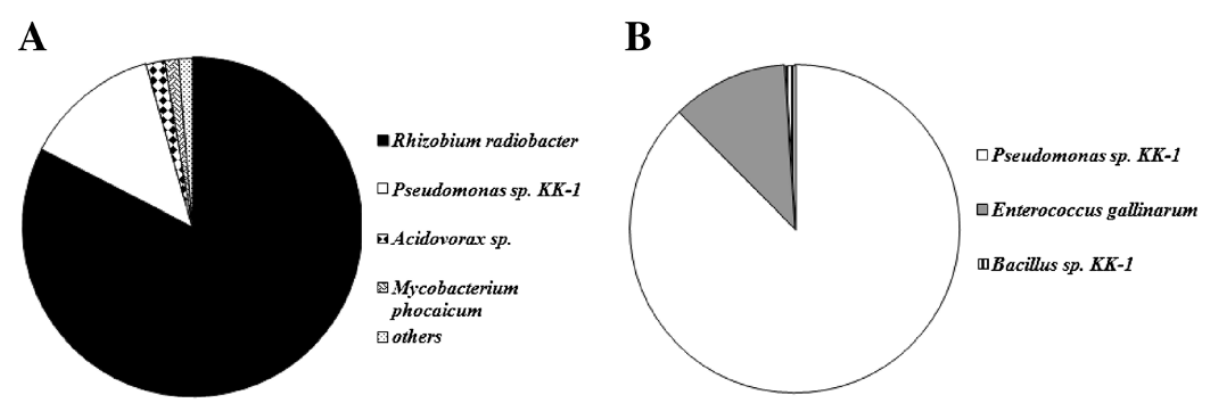

Figure 5 Diversity and prevalence of bacteria in the digestive tract of newly emerged sand flies that developed in control (A) and sterile rabbit feces inoculated with a mixture of six bacterial isolates (B).

Interestingly, from the complex bacterial community of control feces, two bacterial species, Rhizobium radiobacter and Pseudomonas sp. KK-1, that supported sand fly development to a great extent, also survived pupation and colonized the gut of females most commonly (95.6\% of all isolates) (Figure 5A). Survival of individual bacterial species during fly pupation varied greatly depending on the bacterial strain; M. morganii and Pseudomonas sp. KK-2 were detected in $40 \%$ of females while Bacillus sp. KK-1 was not detectable although due to high larval mortality only two adult females were analyzed (Table 1). The highest prevalence of bacteria in the gut of newly emerged females (44.4\%) was detected from the larval substrate inoculated by the mixture of all six isolates. The highest population size $\left(\sim 10^{3} \mathrm{CFU}\right)$ per gut was recorded for Rhizobium radiobacter and Pseudomonas sp. KK-1 (Table 1). In contrast to results from the complex microbial community, $R$. radiobacter was not recovered and Pseudomonas sp. KK-1 and E. gallinarum were two most frequently detected bacterial taxa in the gut of newly emerged females that developed as larvae in a substrate with the mixture of six isolates (Figure 5B). Sterility of axenic flies (from sterile rabbit feces) was confirmed by a culturing method as well as by PCR of $16 \mathrm{~S}$ rDNA.

In general, before and during pupation, bacteria in the gut lumen are eliminated due to major changes in the gut content and structure and secretion of antimicrobial compounds [26]. However, transstadial passage of bacteria from larvae to pupae and adult flies has been reported for $P$. duboscqi [17] and $P$. argentipes [18]. In $P$. duboscqi, Ochrobactrum sp. AK was recovered in the midgut and hindgut of $64 \%$ of freshly emerged flies and their counts ranged from $\left(10^{2}\right.$ to $10^{4} \mathrm{CFU}$ per fly). Hurwitz et al. [18] showed that $B$. subtilis added $\left(10^{7} \mathrm{CFU}\right)$ to the $P$. argentipes (L4) larval medium (fermented rabbit food and feces) either sterilized or control (with other live bacteria) survived pupation and was recovered in $75 \%$ of flies in concentration $7.2 \times 10^{3}$ CFU per fly (sterilized medium) and $74 \%$ of flies with $3.9 \times 10^{4} \mathrm{CFU}$ per fly (control medium). The prevalence and concentration of bacteria in those two studies was higher compared to ours; this may be due to differences in survivability between bacteria and also differences in the gut structure and pupation between the sand fly species. Furthermore, Hurwitz et al. [18] reported that $P$. argentipes failed to develop in a sterile substrate, which is in contrast to our study with L. longipalpis. However, so far, we have not been able to raise P. papatasi on sterile rabbit feces (data not shown) and it may be that there is a difference in dependence on bacteria between Old World and New World sand fly species. Preference of Phlebotomus sp. larvae for non-autoclaved food is also indicated in the study of Volf and Volfova [27] although more data on the significance of microbes in larval development of sand flies in this genus are needed.

\section{Conclusions}

Females of the phlebotomine sand fly L. longipalpis use bacteria-mediated cues to locate an appropriate oviposition substrate. In addition, although bacteria contribute to larval development, an axenic system to raise $L$. longipalpis is reported. Some bacteria such as $R$. radiobacter and Pseudomonas sp. KK-1 support larval development to the same extent as a complex bacterial community, survive fly pupation, and colonize the digestive tract of newly emerged females. With the establishment of the axenic rearing system, this study opens new venues to study the effect of bacteria on the gut epithelial immunity and vector competence of sand flies for Leishmania parasites.

Competing interests

The authors declare that they have no competing interests. 


\section{Authors' contributions}

LZ, KPK, MRO designed the study. KPK conducted the experiments; KPK and $\mathrm{LZ}$ analyzed the data and wrote the manuscript. MRM maintained the laboratory colony of L. longipalpis and provided blood-fed females for the oviposition assays. All authors read and approved the final manuscript.

\section{Acknowledgements}

This study was supported by the $\mathrm{NIH}$ grant P20-RR017686 to LZ. MRO was supported with NIH grants R01 Al074691 and R21 Al088051-01. This is contribution no. 13-009-J from the Kansas Agricultural Experiment Station.

Received: 23 April 2012 Accepted: 9 July 2012

Published: 24 July 2012

\section{References}

1. Killick-Kendrick R: The biology and control of phlebotomine sand flies. Clin Dermatol 1999, 17:279-289.

2. Feliciangeli MD: Natural breeding places of phlebotomine sandflies. Med Vet Entomol 2004, 18:71-80.

3. Abecia L, Fondevila M, Balcells J, Edwards JE, Newbold C, McEwan NR: Molecular profiling of bacterial species in the rabbit caecum. FEMS Microbiol Lett 2005, 244:111-115.

4. Micheland RJ, Combes S, Monteils V, Cauquil L, Gidenne T, Fortun-Lamothe $\mathrm{L}$ : Molecular analysis of the bacterial community in digestive tract of rabbit. Anaerobe 2010, 16:61-65.

5. Dougherty M, Guerin PM, Ward RD: Identification of oviposition attractans for the sand fly Lutzomyia longipalpis (Diptera, Psychodidae) in volatiles of feces from vertebrates. Physio Entomol 1995, 20:23-32.

6. El Naiem DA, Ward RD: Oviposition attractants and stimulants for the sandfly Lutzomyia longipalpis (Diptera: Psychodidae). J Med Entomol 1992, 29:5-12.

7. El Naiem DA, Ward RD: Response of the sandfly Lutzomyia longipalpis to an oviposition pheromone associated with conspecific eggs. Med Vet Entomol 1991, 5:87-91.

8. Dougherty MJ, Ward RD, Hamilton JGC: Evidence for the accessory glands as the site of production of the oviposition attractant and/or stimulant of Lutzomyia longipalpis (Diptera: Psychodidae). J Chem Ecol 1992, 18:1165-1175.

9. Dougherty M, Hamilton G: Dodecanoic acid is the oviposition pheromone of Lutzomyia longipalpis. J Chem Ecol 1997, 23:2657-2671.

10. Wasserberg G, Rowton ED: Sub-additive effect of conspecific eggs and frass on oviposition rate of Lutzomyia longipalpis and Phlebotomus papatasi. J Vect Entomol 2011, 36(Suppl 1):S138-S143.

11. Radjame K, Srinivasan R, Dhanda V: Oviposition response of phlebotomid sandfly Phlebotomus papatasi to soil bacteria isolates from natural breeding habitats. Indian J Exp Biol 1997, 35:59-61.

12. Romero A, Broce $A$, Zurek L: Role of bacteria in the oviposition behaviour and larval development of stable flies. Med Vet Entomol 2006, 20:115-121.

13. Zurek L, Schal C, Watson DW: Diversity and contribution of the intestinal bacterial community to the development of Musca domestica (Diptera: Muscidae) larvae. J Med Entomol 2000, 37:924-928.

14. Perotti MA, Lysyk TJ: Novel growth media for rearing larval horn flies, Haematobia irritans (Diptera: Muscidae). J Med Entomol 2003, 40:22-29.

15. Hollis JH, Knapp FW, Dawson KA: Influence of bacteria within bovine feces on the development of the face fly (Diptera: Muscidae). Environmental Entomology 1985, 14:568-571.

16. Pumpuni CB, DeMaio J, Kent M, Davis JR, Beier JC: Bacterial population dynamics in three anopheline species: impact on Plasmodium sporogonic development. AmJTrop Med Hyg 1996, 54:214-218.

17. Volf $\mathrm{P}$, Kiewegova A, Nemec A: Bacterial colonization in the gut of Phlebotomus duboscqi (Diptera: Psychodidae): transtadial passage and the role of female diet. Folia Parasitol 2002, 49:73-77.

18. Hurwitz I, Hillesland H, Fieck A, Das P, Durvasula R: The paratransgenic sand fly: A platform for control of Leishmania transmission. Parasit Vectors 2011, 4:1-9.

19. Hugenholz P, Pitulle C, Hershgerger KL, Pace NR: Novel division level bacterial diversity in a Yellowstone hot spring. J Bacter 1998, 180:366-376.

20. Poyaert C, Quesnes G, Trieu-Cuot P: Sequencing the gene encoding manganese-dependent superoxide dismutase for rapid species identification of Enterococci. J Clin Microbiol 2000, 38:415-418.
21. Altschul SF, Gish W, Miller W, Myers EW, Lipman DJ: Basic local alignment search tool. J Molec Biol 1990, 215:403-410.

22. Dougherty MJ, Guerin PM, Ward RD: Identification of oviposition attractants for the sandfly Lutzomyia longipalpis (Diptera: Psychodidae) in volatiles of faeces from vertebrates. Physiol Entomol 1995, 20:23-32.

23. Gouveia C, Asensi MD, Zahner V, Rangel EF, DeOliveira SMP: Study of the bacterial midgut microbiota associated to different brazilian population of Lutzomyia longipalpis (Lutz \& Neiva) (Diptera: Psychodidae). NeotropEntomol 2008, 37:597-601.

24. Hillesland H, Read A, Subhadra B, Hurwitz I, McKelvey R, Ghosh K, Das P, Durvasula R: Identification of aerobic gut bacteria from the Kal Azar vector, Phlebotomus argentipes: a platform for potential paratransgenic manipulation of sand flies. AmJTrop Med Hyg 2008, 79:881-886.

25. do Fazito Vale V, Pereira MH, Gontijo NF: Midgut pHprofile and protein digestion in the larvae of Lutzomyia longipalpis (Diptera: Psychodidae). J Insect Physiol 2007, 50:1151-1159.

26. Lantova L, Volf P: The development of Psychodiella sergenti (Apicomplexa: Eugregarinorida) in Phlebotomus sergenti (Diptera: Psychodidae). Parasitology 2012, 139:726-734.

27. Volf $P$, Volfova $V$ : Establishment and maintenance of sand fly colony. I Vector Ecol 2011, 36(Suppl 1):S1-S9.

doi:10.1186/1756-3305-5-145

Cite this article as: Peterkova-Koci et al: Significance of bacteria in oviposition and larval development of the sand fly Lutzomyia longipalpis. Parasites \& Vectors 2012 5:145.

\section{Submit your next manuscript to BioMed Central and take full advantage of:}

- Convenient online submission

- Thorough peer review

- No space constraints or color figure charges

- Immediate publication on acceptance

- Inclusion in PubMed, CAS, Scopus and Google Scholar

- Research which is freely available for redistribution 